\title{
ETHNO-LINGUISTIC VITALITY OF KOCH
}

\author{
Satarupa Dattamajumdar \\ Former Project Director, ICSSR, New Delhi
}

\section{THE KOCH LANGUAGE}

The Koch language is spoken in the states of Assam (Goalpara, Nagaon, Dhubri, Kokrajhar, Chirang, Bongaigao, Barpeta, Baksa, Udalguri, Karbi Anglong, Golaghat districts), Meghalaya (West Garo Hills, South-West Garo Hills, South Garo Hills and East Khasi Hills Districts). Koches are found in West Bengal (Northern part) and also in Bangladesh. The speaker strength of Koch in India according to 2011 census is 36,434 . Koch community is the bilingual speakers of Assamese, Bengali, Garo, Hindi, and English. Contact situations of Koch with Assamese and Bengali languages have made the language vulnerable to language shift. The UNESCO report mentions Koch as 'Definitely Endangered'. Koch has gained the status of a scheduled tribe in Meghalaya in 1987. Kondakov (2013) traces six distinct dialects of Koch, viz., Wanang, Koch-Rabha (Kocha), Harigaya, Margan, Chapra and Tintekiya. He (2013:24) states, "The relationship between the six Koch speech varieties are rather complex. They represent a dialect chain that stretches out from Koch-Rabha in the north to Tintekiya Koch in the south." This is diagrammatically represented as - Koch-Rabha(Kocha) $\rightarrow$ Wanang $\rightarrow$ Harigaya $\rightarrow$ Margan, Chapra $\rightarrow$ Tintekiya where the adjacent dialects exhibit more lexical similarity than those at the ends. Nine ethno-linguistic varieties of Koch (also mentioned in Kondakov, 2013:5) have been reported during field investigation. These are Harigaya, Wanang, Tintekiya, Margan, Chapra, Satpariya, Sankar, Banai and Koch Mandai.

The Koch people practice animism as their traditional religion and also practice some of the practices of Hinduism in the form of Sakti worship. Some Koch-Rabha people also follow Christianity.

\section{LINGUISTIC FILIATION OF KOCH}

Damant (1880:252) provides us with a classification of the Bodo group of languages which he termed as 'Kachári-Koch sub-family'. Koch is considered

\footnotetext{
1 Depending mainly upon the extent of intergenerational language transmission, UNESCO (Ref: http//www. unesco.org/languages. atlas/accessed on 02.09.2018: 13:20 hours) establishes six degrees of vitality/endangerment - 'safe', 'vulnerable', 'definitely endangered', 'severely endangered', 'critically endangered' and 'extinct'.
} 
202012

as one of the languages of the group, having speech varieties. The classification provided by Damant (1880) is presented in the following.

\section{Table-1}

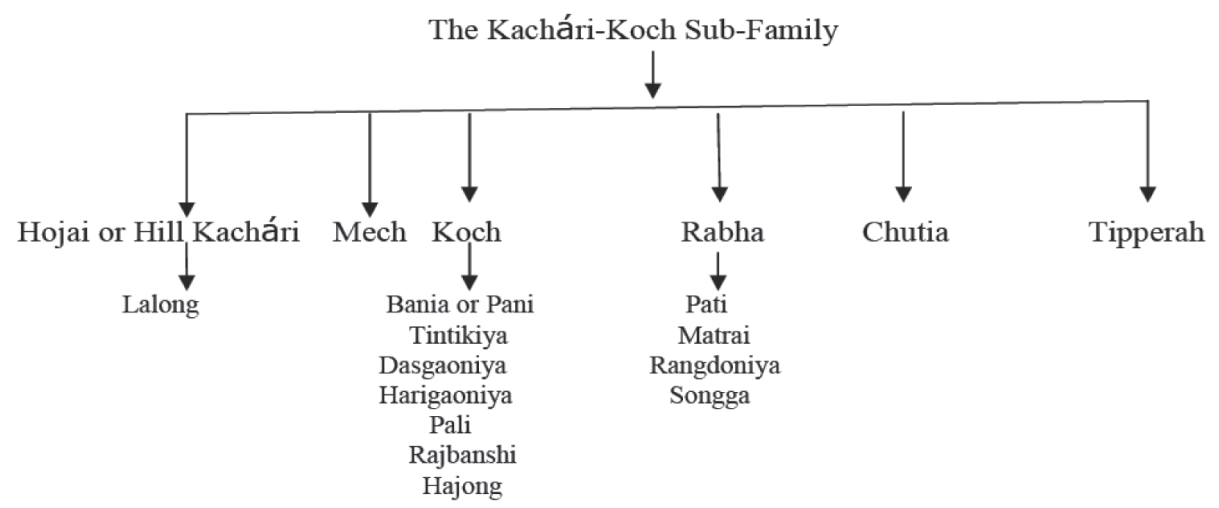

According to Grierson (1903) Koch is considered under Garo sub-group in the name 'Koch dialects' along with Achik, Abeng, Atong, etc. The language is classified as a language of the Bodo group. The classification is presented below.

Table-2

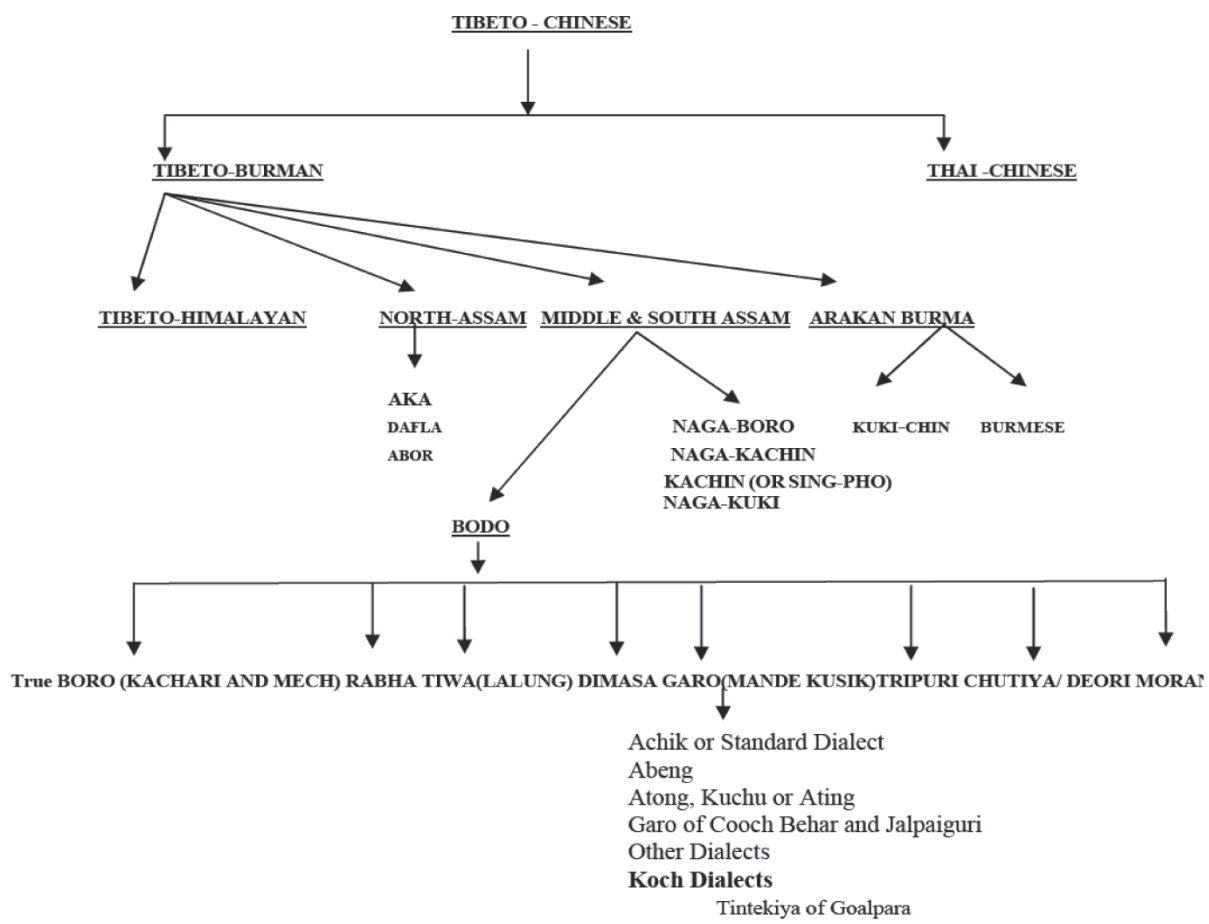




\section{LINGUISTIC VITALITY: THE CONCEPTUAL FRAMEWORK}

As the socio-linguistic profile of a language is studied in terms of geopolitical units, domains and modes of language use, such a study focuses on the existence and status of other languages in the ecology or linguistic network. According to McConnell (1987:360) "A language of high vitality will generate strong centrifugal forces, which will be resolved on contact with other languages of lower vitality, into centripetal (pressure) forces. This in turn will give rise to a tendency of lower vitality languages not to increase their range and level of usage, but rather to decrease the same slowly.... The vitality ratings of each of the languages in contact, strike some kind of balance among existing opposing forces, which in turn influence the language vitality of each of the languages in place and hence result in functional stability and functional loss or gain." As a result in course of time some kind of imbalance is created among existing opposing forces which influence the language vitality of each of the languages in the network. This ultimately results into functional loss or gain of a language. The matter of language maintenance and loss in a competitive linguistic ecology has been viewed significantly by Martin (2009:123) as, "... that cultures function in an information space which the bearers of that particular culture create for themselves. As the information spaces may overlap, people are often living simultaneously within a spread zone of two or even more information spaces. Each such information space has a core that attracts people by satisfying cultural needs and providing a possible social identity. The matter of language maintenance or loss is a competition between two or more ethno-linguistic cultures that are in contact. The outcome of each particular contact situation depends on the choices that individuals make between these competing cultural affiliations and social identities." Therefore, Koch has been studied in the bilingual context of Assamese, Bengali, Boro, Garo, Hindi, and English. Martin (2009:125) classifies the vitality factors of a language into objective vitality and subjective vitality. Objective vitality refers to the systematic descriptions of Status factors, Demographic factors, Institutional Support and Control factors which characterize the ethno-linguistic group and usage of their language. On the other hand, subjective vitality refers to the perception of the objective vitality by the in-group members of the speech community and by the members of other community in contact with the in-group community. The use and choice of language in close interaction seems to be relevant from the point of view of language identity.

The notion of ethno-linguistic vitality was introduced by Giles, Bourhis and Taylor (1977). It is viewed as a distinct collective behaviour of a group within an inter group situation. Status, demography and institutional support are considered to be the major criteria for the vitality of an ethnic group. In order to determine the vitality status of the community the economic status, social status, socio-historical status and language status (within the community 
and outside the community) are considered as a whole. The determinants to understand the vitality of a speech community from the point of view of demography are-distribution of the population and the numerical data of speakers' strength, birth rate, inter-ethnic marriages, immigrant and emigrant population. Apart from these, institutional support (both formal and informal) of the language in the domains of mass media, education, government jobs and industry plays a crucial role in determining the vitality status of a language. The extent of use of the language in the religious and cultural domains of the speech community is also taken into consideration in order to understand the linguistic vitality of the community. The notion of different components involved in vitality of an ethic group as proposed by Giles, Bourhis and Taylor (1977) is presented below.

\section{Chart-1 \\ A Taxonomy of the Structural Variables Affecting Ethno-linguistic Vitality \\ by H. Giles, R.Y. Bourhis and D.M. Taylor (1977)}

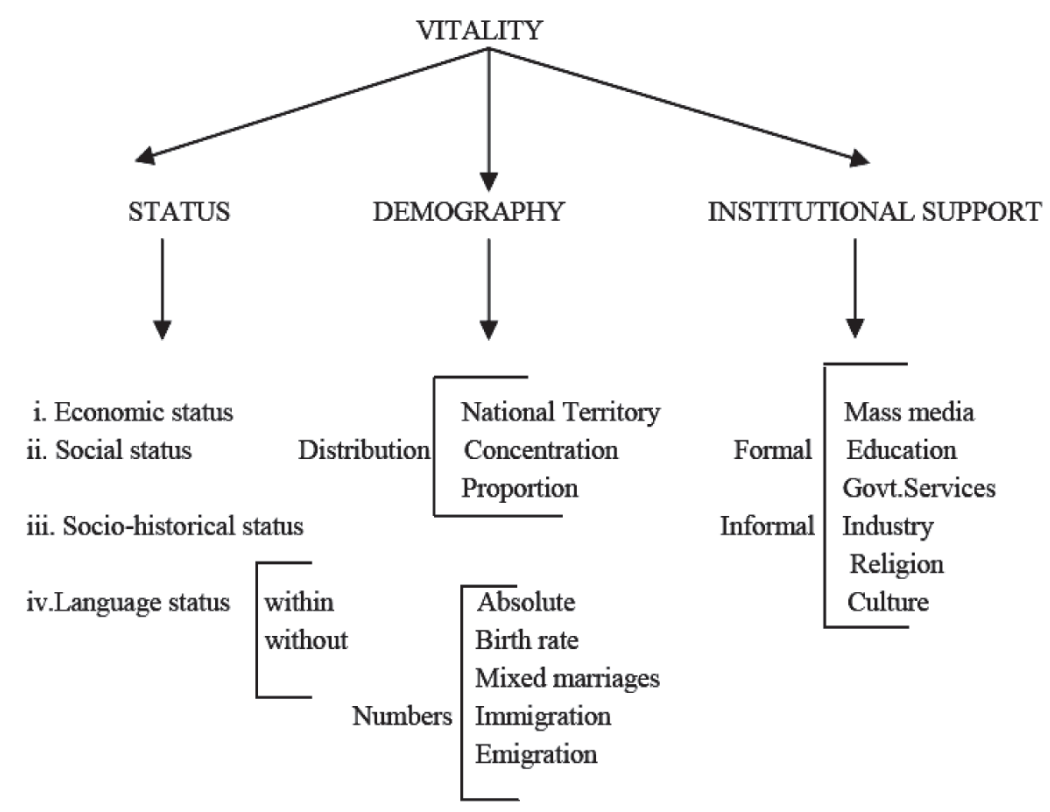

According to Martin (2009: 123) “...ethnolinguistic vitality is a function of discursive factors such as values, beliefs and attitudes in a particular linguistic community. These discursive factors are only partly influenced by objective factors such as legal status, economic strength and the education system. Although the objective factors are necessary preconditions of vitality, they are not sufficient factors. Thus, vitality should not be measured by objective criteria, but from the reflection of these in the group's common knowledge." 
Keeping in view the notion of ethno-linguistic vitality the study of language endangerment of Koch will be carried out both from the macro-linguistic and micro-linguistic perspectives.

\section{DIMENSIONS OF LANGUAGE DEVELOPMENT}

In order to have a composite picture of the development of the Koch language with reference to Meghalaya in particular, the Ausbau (language by elaboration) dimensions proposed by McConnell (1987) seems relevant. McConnell (1987:164) states, "What is plausible is that a language may gain in dominance simply by its use in a larger number of domains (range)." This is significant in determining the vitality of a language. Therefore, in order to have a glimpse at the concordance of the language and the social reality the functional status of Koch has been examined by its use in various social domains.

Taking cue from Kloss $(1966,1967)$ and as also illustrated in McConnell (1987) the dimensions of language growth according to four levels of development, a requirement for language planning, has been examined to view the language development profile of Koch. In order to determine the linguistic status of Koch, the following four basic aspects have been taken into consideration as a theoretical construct.

i. Policy

ii. Codification

iii. Elaboration and

iv. Implementation

Chart -2

Language Planning Dimensions of Language Development (McConnell: 1987)

Levels

of

Growth

\begin{tabular}{|c|c|c|c|}
\hline & & & Industry \\
\hline & & & Legislature \\
\hline $\begin{array}{l}\text { Country } \\
\text { Official }\end{array}$ & $\begin{array}{l}\text { Descriptive } \\
\text { Studies }\end{array}$ & $\begin{array}{l}\text { Non Narrative- } \\
\text { Learned * }\end{array}$ & Judiciary \\
\hline $\begin{array}{c}\text { State } \\
\text { Official }\end{array}$ & Grammar & $\begin{array}{l}\text { Non Narrative- } \\
\text { Refined * }\end{array}$ & $\begin{array}{l}\text { Govt. } \\
\text { Administration }\end{array}$ \\
\hline $\begin{array}{l}\text { Regional } \\
\text { Official }\end{array}$ & Dictionary & $\begin{array}{l}\text { Non Narrative- } \\
\text { Popular * }\end{array}$ & Mass media \\
\hline Promoted & Orthography & Narrative Prose* & Schools \\
\hline Proscribed & Script & Narrative Verse* & Religion \\
\hline
\end{tabular}
(1) Policy
(2) Codification
(3) Elaboration
(4) Implementation 
Each of the above mentioned aspects will be discussed at length for examining levels of growth of the Koch language.

\subsection{POLICY}

Policy refers to the decision of the organization (govt./non-govt.) constituted formally regarding "(1) the functional allocation of codes within a speech community or (2) the characteristics of one or more codes within the code matrix (linguistic repertoire) of such a community."(McConnell, 1987:183) Constitutionally, as the protection is being provided to the communities, religion and their linguistic rights in the Indian context, Koch, the language of a minority community is constitutionally safeguarded. But the question arises as whether such policy is merely symbolic or whether it really safeguards the language from the functional point of view. Koch has its structural autonomy and is considered a separate language. This has been established by the genealogical classifications provided by the scholars starting from the nineteenth century to the first decade of the twenty first century.

\subsection{CODIFICATION}

Codification of norms refers to the phenomenon when a selection was made regarding the language variety by some agency, e.g., individual having authority starts out to make dictionaries, spelling manuals, grammars, etc. to fix the variety so that a norm is established and the members of the speech variety agrees to that part. The intellectual credibility must be there for codification.

It has been observed that Koch has an orthographic status. Assamese/ Bengali script was adopted initially but later Roman script is being used to write the language. The characteristic features of Koch pronunciation and its relationship with Assamese alphabets and Roman alphabets have been discussed in Kondakov and Koch (2009:xi). In the present-day situation, the speakers of the Koch community prefer to use the Assamese/Bengali script.

The Koch language is codified to some extent. It has a brief grammatical sketch (Koch, 2014). Dictionary is also available in the language (Koch, 2016 and Kondakov, 2018). All these are non-governmental efforts. Book on Koch vocabulary (Koch, 2003) is also available.

\subsection{ELABORATION OF FUNCTION}

Elaboration of function refers to different categories of literature produced in the language. The extent of elaboration in a language enables us to determine 
the functional status of a language. The availability status of the literary works of various types like narratives, non-narratives, lyrics, plays, songs, fictions and other non-narratives are available in the Koch language. Translation works in Koch is a recent phenomenon. Learned and refined literatures are yet to be produced in the language.

\subsection{IMPLEMENTATION}

Implementation refers to the use of a language in the social domains like religion, school, mass media, government administration, legislation, judiciary, manufacturing/sales/service industry and efforts to promote the use of the language on the basis of the planning and decision taken by social agencies.

As regards the implementation of the Koch language in various social domains, it is observed that the language is used in its spoken form in the traditional (animism) religious practice and Hinduism (which has been adopted in a relatively later period). No written document is available in Koch for these religious practices.

Koch has no place in the school curriculum followed in the government schools of the state. Even no pedagogical effort for the Koch language has been observed by the non-govt. agencies. But four primers are published in Koch in 2014. Language teaching materials are also available in Koch, which includes grammar, dictionary, books of conversation and books for learning the Koch language structure. But all these are non-governmental efforts.

As regards mass media, news-sheets and bulletins are not available in Koch. Bilingual (Assamese and Koch) and multilingual (Assamese, Bengali, English and Koch) magazines/periodicals are available which are published by Koch Krorang Mathop (Koch Literary Society) and Meghalaya Koch Association. Koch is used occasionally in the audio-visual media. Composite programs on Koch are broadcast from All India Radio, Tura and folk songs and dance are telecast by Doordarshan, Tura.

There is no use of the Koch language in the domains of government administration, legislation and judiciary.

Koch is found to be used as one of the languages in small scale/cottage industries along with Assamese, Hindi and Bengali. The language is reported not to be used in the large or medium scale manufacturing and sales industry. The language is also used in the local cottage industries and to some extent at the village level service industry.

The above discussed developmental status of the Koch language which has been dealt with in the light of each of the dimensions of language planning is graphically represented in the following chart. 


\section{Chart-3}

Language Planning Dimensions of Koch Language Development

(The Levels of Growth is shown in the vertical plane from bottom to top and the Language Planning Dimensions are shown in the horizontal plane)

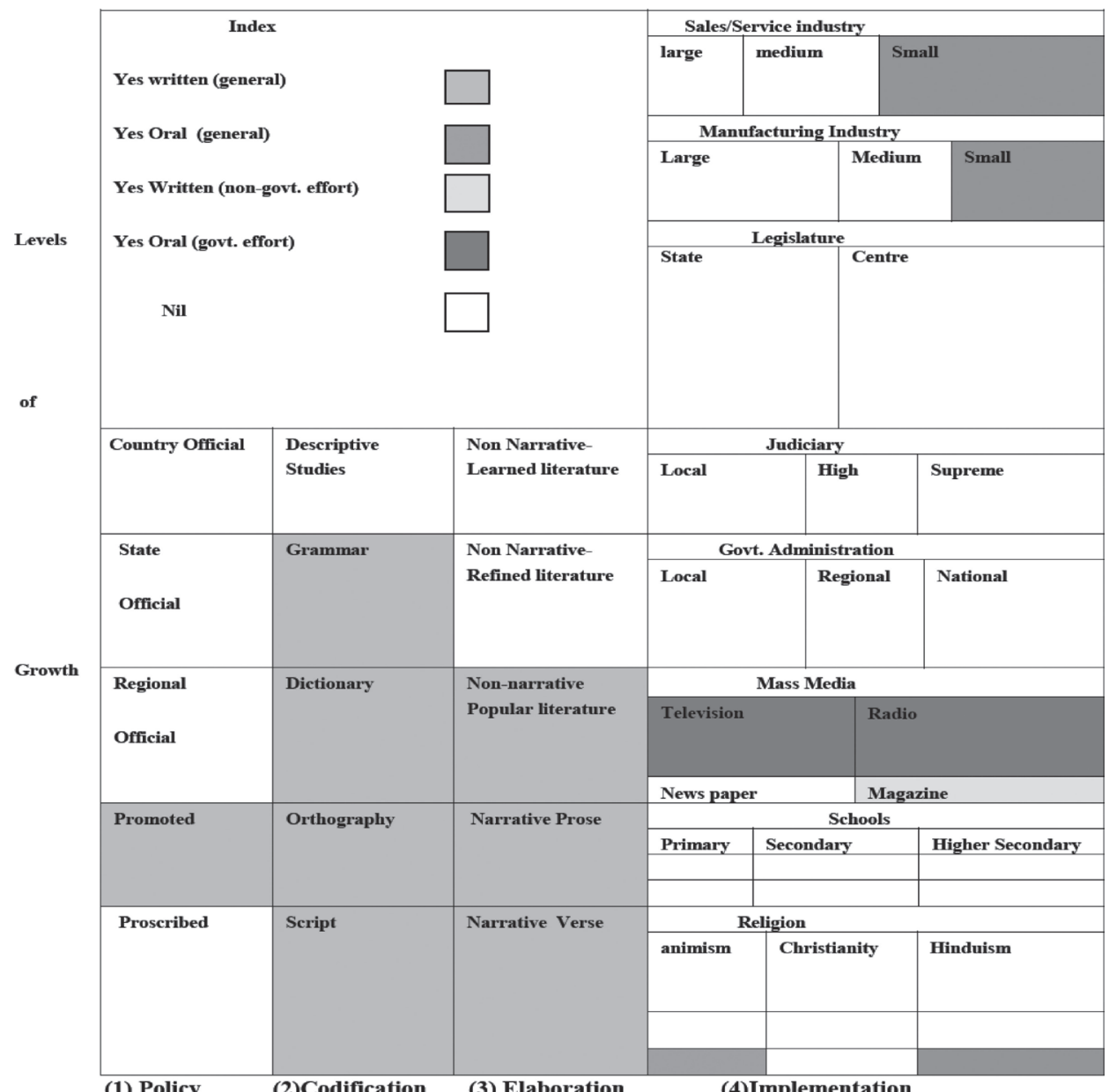

$\begin{array}{llll}\text { (1) Policy } & \text { (2)Codification } & \text { (3) Elaboration } & \text { (4)Implementation }\end{array}$

\section{EXPLORING ETHNO-LINGUISTIC VITALITY OF KOCH}

Keeping in view the above observation and finding the study will attempt to examine the socio-linguistic situation of Koch in the light of the factors (nine) of ethno-linguistic vitality proposed by UNESCO (2002-2003) which are mentioned in the following.

(1) Absolute number of speakers

(2) Intergenerational language transmission

(3) Community member's attitude towards their own language

(4) Shifts in domains of language use 
(5) Governmental and Institutional language attitudes and policies, including official status and use

(6) Type and quality of documentation

(7) Response to new domains and media

(8) Availability of materials for language education and literacy

(9) Proportion of speakers within the total population

The vitality status of Koch has been discussed from the point of view of each of the above mentioned factors in the following.

\subsection{ABSOLUTE NUMBER OF SPEAKERS}

The speaker strength of Koch in India according to 2011 census is 36,434 (as mentioned earlier). In Meghalaya it is 23,199 whereas, in Assam it is 12,550 and in West Bengal it is only 427 (2011 census). Therefore, the main concentration of the Koch speakers is found to be in Meghalaya where they are declared a scheduled tribe. A decadal increase in the number of the Koch speakers' strength is also evident. When 2001 and 2011census reports' data are compared, an increase of 17.08 percent in the speaker strength can be observed.

\subsection{INTERGENERATIONAL LANGUAGE TRANSMISSION}

Language transmission that is, handing over the norms and rules of language/ mother tongue use to the future generation is considered integral for the survival of a language (also mentioned in the earlier works of the author). The use of Koch, as mother tongue in different domains of social life reveals the picture that Koch is frequently used by a high percentage of Koch respondents in the home domain with the older generation especially with grandparents in Meghalaya. But when it comes to the use of the language with spouse and children, the percentage of respondents reduce (see below in Graph-2). The inter-ethnic marriage with the Garo, Bodo and Assamese speech communities and the socio-political and cultural domination of Bengali (an impact from the colonial period) has dampened the use of Koch, the mother tongue for the future generation to a great extent in Assam but less in Meghalaya. The mothers from other communities without any skill of using the Koch language create a hiatus in the intergenerational transmission of the language while grooming their children. Even when there is an effort on the part of the father or other older family members to teach Koch to the children, the lack of the Koch language skill of the mother proves detrimental to the maintenance of the mother tongue for the next generation. This is especially relevant in the villages of Assam though the bordering Koch villages (which share the border with the West Garo Hills district of Meghalaya) like Manjurigaon exhibits language transmission to the younger generation. Moreover, there are Koch villages in Assam where the Koch language is not used at all. Therefore, the 
question of intergenerational transmission of the language does not arise at all in those villages. The tendency of the Koch speakers to identify themselves with Rabha (a scheduled tribe of Assam) in order to enjoy the benefits of the schedule tribe status has also proved detrimental in maintenance of the Koch language in Assam. The speakers of Rajbangsi language of Cooch-behar, who are undoubtedly the Koch speakers in origin, exhibit a complete shift of language from Koch, their Tibeto-Burman mother tongue to Rajbangsi, an Indo-Aryan variety of language for generations together. Thus the intergenerational transmission of Koch, the mother tongue is evident only in the Koch inhabiting districts of Meghalaya. The intergenerational language transmission is observed to be weak in Assam and rare in West Bengal.

\subsection{COMMUNITY MEMBER'S ATTITUDE TOWARDS THEIR OWN LANGUAGE}

Attitude plays a crucial role in the social behaviour of an individual as it defines and promotes certain behaviour. People's reaction towards a language reveals their perception regarding the speakers of that variety - their social, political and economic setup. Fasold (1984: 148) suggests that the attitude towards a language is often the reflection of the attitudes towards the members of that speech community. Dattamajumdar (2003:50) states, "The concept of language attitude automatically brings into consideration the concept of motives - the instrumental motive and the integrative motive. When the knowledge of a language is considered to be a prestige marker, the acquisition of that language is said to be instrumental. On the other hand, if the learner wishes to learn a language in order to identify himself with the members of the speech community, the motive is called an integrative one. However, motivation which arises whether from a sense of academic success or from a sense of communicative success motivates one's attitude to learn and speak a foreign language or a second language."

The language attitude of the Koch speech community has been examined from the point of view of language proficiency, language preference in the present section. It is pertinent to mention here that as the speaker strength is much higher in Meghalaya and as the language is found to be maintained more in Meghalaya than in Assam, the study of language attitude of Meghalaya has been discussed elaborately. The observation of the study of language attitude carried out in Assam has been discussed in a nutshell in the present study.

\subsubsection{LANGUAGE ATTITUDE OF THE KOCH SPEAKERS OF MEGHALAYA}

The present section examines the language attitude of the Koch speakers of Meghalaya, towards their mother tongue and other tongues in the neighbourhood. The survey has been carried out by administering a socio-linguistic questionnaire. The sample size of the study, i.e., the number of respondents taken is hundred. 
Language attitude has been studied from the point of view of Language Proficiency and Language Preference in Mass Media.

\subsubsection{LANGUAGE PROFICIENCY}

The four skills required for using a language, i.e., - Listening, Speaking, Reading and Writing have been taken into consideration in order to examine the language proficiency of an individual Koch respondent. The following tables provide us with a picture of language proficiency of the Koch speakers of Garo Hills of Meghalaya in terms of four point scale - 'good', 'average', 'little' and 'nil'.

Table 3. Self-reported listening skill of the languages (percentage of respondents)

\begin{tabular}{|l|l|l|l|l|l|l|l|}
\cline { 2 - 7 } \multicolumn{1}{c|}{} & Koch & Assamese & Garo & Bengali & Hindi & Hajong & English \\
\hline Good & 97.00 & 91.00 & 82.00 & 88.00 & 82.00 & 63.00 & 39.00 \\
\hline Average & 01.00 & 04.00 & 09.00 & 04.00 & 08.00 & 01.00 & 09.00 \\
\hline Little & 02.00 & 02.00 & 03.00 & 04.00 & 03.00 & 0.00 & 03.00 \\
\hline Nil & 0.00 & 03.00 & 06.00 & 04.00 & 07.00 & 36.00 & 49.00 \\
\hline
\end{tabular}

Table 4. Self-reported speaking skill of the languages (percentage of respondents)

\begin{tabular}{|l|l|l|l|l|l|l|l|}
\cline { 2 - 7 } \multicolumn{1}{c|}{} & Koch & Assamese & Garo & Bengali & Hindi & Hajong & English \\
\hline Good & 98.00 & 91.00 & 83.00 & 87.00 & 80.00 & 65.00 & 33.00 \\
\hline Average & 0.00 & 08.00 & 09.00 & 07.00 & 10.00 & 0.00 & 08.00 \\
\hline Little & 02.00 & 01.00 & 02.00 & 02.00 & 03.00 & 0.00 & 08.00 \\
\hline Nil & 0.00 & 03.00 & 06.00 & 04.00 & 07.00 & 35.00 & 51.00 \\
\hline
\end{tabular}

Table 5. Self-reported reading skill of the languages (percentage of respondents)

\begin{tabular}{|l|l|l|l|l|l|l|l|}
\cline { 2 - 7 } \multicolumn{1}{c|}{} & Koch & Assamese & Garo & Bengali & Hindi & Hajong & English \\
\hline Good & 89.00 & 90.00 & 48.00 & 87.00 & 67.00 & 41.00 & 45.00 \\
\hline Average & 04.00 & 04.00 & 23.00 & 03.00 & 12.00 & 09.00 & 06.00 \\
\hline Little & 07.00 & 03.00 & 20.00 & 04.00 & 13.00 & 11.00 & 0.00 \\
\hline Nil & 0.00 & 03.00 & 09.00 & 06.00 & 08.00 & 39.00 & 49.00 \\
\hline
\end{tabular}

Table 6. Self-reported writing skill of the languages (percentage of respondents)

\begin{tabular}{|l|l|l|l|l|l|l|l|}
\cline { 2 - 7 } \multicolumn{1}{c|}{} & Koch & Assamese & Garo & Bengali & Hindi & Hajong & English \\
\hline Good & 60.00 & 81.00 & 26.00 & 73.00 & 49.00 & 24.00 & 50.00 \\
\hline Average & 05.00 & 05.00 & 15.00 & 05.00 & 18.00 & 03.00 & 05.00 \\
\hline Little & 35.00 & 07.00 & 46.00 & 13.00 & 21.00 & 32.00 & 01.00 \\
\hline Nil & 0.00 & 07.00 & 13.00 & 09.00 & 12.00 & 41.00 & 44.00 \\
\hline
\end{tabular}

The linguistic proficiency that is claimed by the Koches brings into light mainly the presence of seven languages- Koch, the mother tongue, Assamese, 
Garo, Bengali, Hindi, Hajong and English in their communication network. The languages in which the respondents claim that their proficiency is 'Good' is presented graphically in the following.

\section{Graph-1}

Respondents who Claim to be 'Good'(most proficient) across the Four Language Skills in Koch, Assamese, Garo, Bengali, Hindi, Hajong and English

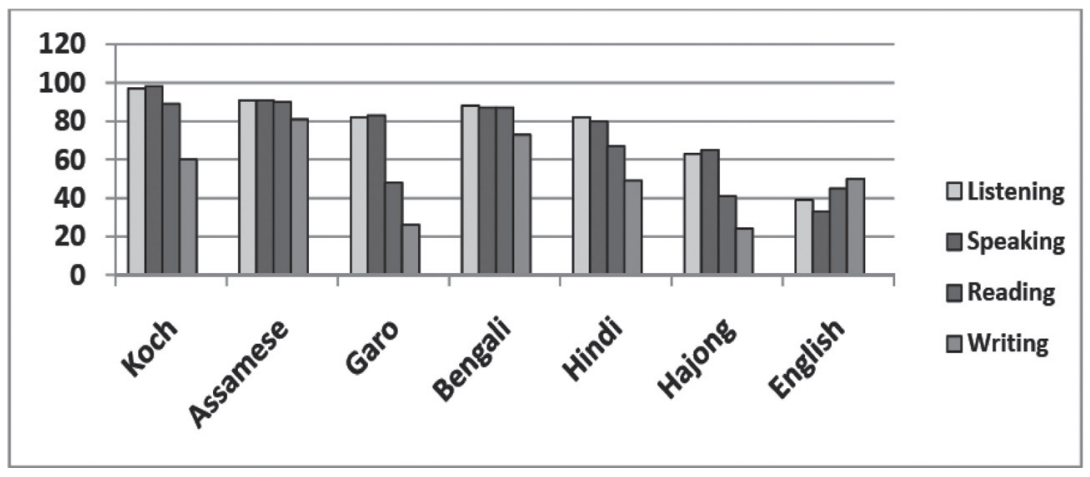

Considering the effect of four skills cumulatively that determines the degree of proficiency in particular language(s), the situation can be summarised in the following way.

i. Most of the Koch respondents claim good proficiency primarily in Assamese and then in Garo, Bengali and Hindi in respect to listening and speaking skills.

ii. As regards the writing skill the proficiency level of Assamese and Bengali is found to be exceeding the mother tongue, Koch. The socio-political dominance of the Bengali and the Assamese languages since $18^{\text {th }} \mathrm{c}$. can be said to be the major factor that exerted immense pressure on the Koch language. This is also due to the formal education in Assamese and Bengali as subjects taught in the schools of Garo Hills district of Meghalaya, whereas, Koch is not taught at any level of school education.

iii. In spite of the fact that Bengali is an Indo-Aryan language and Koch a Tibeto-Burman language, the continual migration of the Bengali population, which was encouraged by the then British administrators influenced every aspect of social life as a super-strate culture in the Garo Hills.

iv. The impact of Garo, the language of the numerically strong neighbouring speech community also exerted pressure in case of listening and speaking skills.

v. A good deal of the impact of Hindi is found, which will be discussed at length in the following section dealing with language preference. 
vi. Hajong being a language of the neighbouring community has influenced the Koches mainly in terms of listening and speaking skills.

vii. Though proficiency in the English language is evident among fifty percent of the Koch speakers in respect to reading and writing (due to formal education), the percentage of respondents with proficiency in English in terms of listening and speaking skills decreases. This might be due to the lack of confidence in the fluent use of the English language (though English is the medium of instruction in most of the schools of Garo Hills).

\subsubsection{LANGUAGE PREFERENCE IN MASS MEDIA}

"Preference of language is indicative of the motivation behind using or choosing a particular language(s). This once again depends on the individual's exposure of the language that he/she receives in the societal domains. Therefore, the preference of language(s) may have integrative motive or instrumental motive" (Dattamajumdar, 2016:140). The preference of a language is determined by the social, political and economic factors across the time. The percentage of the respondents' choice or preference of language(s) as far as mass media is concerned is presented in the following tables.

Table 7. Percentage of respondents preferring languages in audio-visual media

\begin{tabular}{|l|l|l|l|l|l|l|}
\cline { 2 - 6 } \multicolumn{1}{c|}{} & Koch & Assamese & Bengali & Hindi & English & Garo \\
\hline Often & 02.00 & 36.00 & 04.00 & 56.00 & 07.00 & 03.00 \\
\hline Sometimes & 20.00 & 44.00 & 61.00 & 31.00 & 14.00 & 03.00 \\
\hline Never & 78.00 & 20.00 & 35.00 & 13.00 & 79.00 & 94.00 \\
\hline
\end{tabular}

Before discussing the scenario of language preference, it is necessary to mention that the availability status of each of the languages in the audio-visual media (mentioned in the above table) is not at par.

The above table reveals that the Hindi language is preferred 'often' by more than fifty percent of the respondents. The preference of Hindi, an impact of audiovisual media being a pan Indian feature, Koch seems to be no exception to this. Next preference is for Assamese, the availability of programs being obviously good. The scenario is quite weak for Koch, the mother tongue, which might be due to the scanty amount of program available in the media. Programs in the Bengali language is preferred 'sometimes' by more than sixty percent of the respondents, which seems to be the impact of the Bengali migration from the colonial period.

Table 8. Percentage of respondents preferring languages in print media

\begin{tabular}{|l|l|l|l|l|l|}
\hline Koch & Assamese & Bengali & Hindi & English & Garo \\
\hline 02.00 & 62.00 & 47.00 & 26.00 & 59.00 & 06.00 \\
\hline
\end{tabular}


The above table reveals that the Assamese language is preferred by more than sixty percent of the respondents, English stands in the second position and Bengali holds the third position. The reason behind is the good availability status of the printed materials in these languages and due to the formal exposure with the Assamese, Bengali and English languages. As the availability status of the printed materials in Koch is quite less in comparison to other languages in their network, and also due to lack of formal education in mother tongue, only two percent of the respondents claim Koch as their preferred language as far as print media is concerned.

\subsubsection{OBSERVATION ON AGE VARIABLE}

The study which has been carried out on the language attitude of the Koch respondents of Meghalaya, attests the response of respondents belonging to different age groups. With a view to differentiate the response of the respondents belonging to different age groups, the respondents were grouped into four major age groups, viz., Age group-11-20; Age group-21-40; Age group-41-60; Age group-61-80.

The study of the language attitude reflects the response of forty five percent (approx.) respondents belonging to the age group 21-40; thirty-seven percent (approx.) belonging to the age group 41-60; fifteen percent (approx.) belonging to the age group 61-80; and three percent belonging to the age group 11-20. As most of the respondents belong to the age of $21-60$, it can be said that the result of the study essentially reflects the language attitude of the respondents belonging to the age group 21-60. No marked distinction in the language attitude or in other words, no marked variable has been observed in the study depending upon the age groups. This signifies the linguistic solidarity of the speech community. It is pertinent to mention here that as the data was collected in support of the association of the Koch speech community, a consensual approach is attested in the claimed language use and choice, language proficiency and language preference of the respondents.

Therefore, the above enquiry on language proficiency and preference exhibits the integrative motive of the Koch speakers towards their mother tongue. In spite of the dominance of Bengali and Assamese as sociopolitically dominant languages and Hindi as lingua franca of the country (and also the impact of Hindi due to the audio-visual media) the positive attitude of the Koch respondents towards their mother tongue is indicative of language maintenance.

\subsubsection{LANGUAGE ATTITUDE OF THE KOCH SPEAKERS OF ASSAM}

The survey of the language attitude of the Koch speakers of Assam has been carried out by administering the socio-linguistic questionnaire. The sample 
size of the study i.e., the number of respondents taken is hundred. Language attitude has been studied from the point of view of use and choice of Koch in different social domains and from the point of view of language proficiency and language preference in mass media. It is pertinent to mention here that due to the dominance of the Assamese language, the Koch speakers in Assam (which is numerically much less than Meghalaya, i.e., 12,550 according to 2011 census) are found to be more vulnerable to language shift than those in Meghalaya.

The study of language attitude of the Koch respondents reveals the presence of the languages like Assamese, Bengali, Garo, Hindi, Bodo, Rabha, Hajong and English in their speech network, apart from Koch, their mother tongue. The study claims 'good' proficiency in Koch for almost all the respondents in respect to 'listening', 'speaking', 'reading' and 'writing' skills. Eighty to eighty six percent of the respondents claim 'good' proficiency in Assamese in respect to all the four skills. Impact of Bengali is evident among almost fifty percent of the respondents. About sixty to seventy percent of the respondents claim 'good' proficiency in Hindi and about twenty percent claim 'good' proficiency in Garo. In the villages of Assam 'good' proficiency in Bodo as a neighbouring language is claimed among ten to twelve percent (approx.) of the respondents. The claimed language proficiency in Rabha is found to be marginal. It is interesting to note here that although it is reported that there has taken place a merger of the Koch speakers with the Rabha speech community, the study of the claimed language proficiency does not reflect such observation. It seems that the change of linguistic identity of Koches as Rabha in Assam is more or less a socio-political phenomenon. Attitudinally the Koch speech community exhibits integrative motive towards their mother tongue. As regards preference for language(s) in mass media Assamese and Hindi are found to be preferred by most of the Koch speakers. Preference of Koch is marginal in this respect. However, in spite of the dominance of Assamese, the Koch villages (where the study has been conducted) exhibit integrative motive towards maintenance of their mother tongue.

The study essentially reflects the language attitude of the respondents belonging to the age group 21-60. No marked variable has been observed in the study depending upon the age groups.

\subsection{SHIFTS IN DOMAINS OF LANGUAGE USE}

The data of language maintenance of Koch (the mother tongue), in different domains of social life claimed by the respondents reveals the use and choice of language in close interaction. This seems to be relevant from the point of view of language identity.

The integrative/instrumental motive of the speakers towards their mother tongue is reflected in the frequency of the self reported use of their mother tongue in different domains of social life. This in turn also brings into light 
a picture of the opportunity that a speaker gets in using their mother tongue in various social domains of interactions. This also helps in determining the frequency of use of the Koch language objectively. The data of the use of Koch, the mother tongue by the Koch speakers of Meghalaya (presented graphically) explains the domains of language use in terms of frequency based on a four point scale, viz., 'frequently' (that is, many times or regularly), 'occasionally' (that is, happening from time to time, not regular) 'rarely' (that is, not often or seldom) and 'never' (that is, on no occasion or not ever). The observations that can be had from the self reported use of Koch, the mother tongue in different domains of social life are enumerated below.

\section{Graph-2}

\section{Respondents' (in percentage) Self-reported Use of} the Koch Language in Different Social Domains

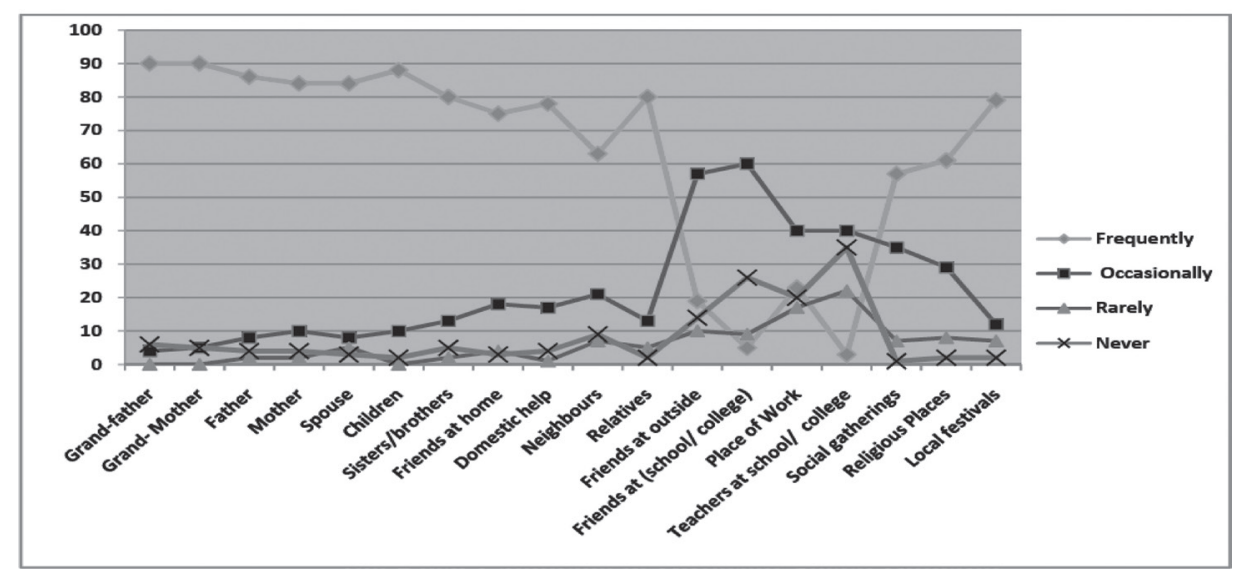

The above graph reveals the self reported 'frequent' use of Koch in different domains of social life. Koch, the mother tongue is used frequently by a high percentage of Koch respondents in the home domain with the older generation especially with grandparents. The percentage of respondents using mother tongue frequently, reduces in cases of parents, spouse, children, sisters/brothers, relatives and friends at home (i.e., with the relatively younger generation). The frequent use of the language with neighbours and domestic help is reported by lesser number of respondents. The scenario changes when it comes to the use of the language in the informal (or 'other than home') domain like friends outside (school or college), teachers in schools/colleges. The percentage of respondents using Koch is also quite low in the formal domain like place of work. But the use of the mother tongue in the formal domain like social gatherings and in religious places shoots up almost as high as the percentage for the use of the language in the home domain. In case of local festival the frequent use of the language has been reported by quite a high percentage of respondents. 
The occasional use of the language has been reported by a low percentage of speakers in their interaction in the informal domain. Only fifty to sixty percent of the respondents report occasional use of the language in their interaction with outside friends, friends at school and college and only forty percent of the respondents report occasional use of the language with the teachers at schools and colleges (formal domain). It is worthy to note that a very low percentage of respondents reports 'rare' and 'never' use of their mother tongue.

As regards the use of the Koch language in different social domains, most of the Koch respondents of different villages of Assam claim 'frequent' use of their mother tongue with the older generation, 'occasional' and 'rare' use of the language in the formal domain like, with friends outside, teachers and in the place of work.

\subsection{GOVERNMENTAL AND INSTITUTIONAL LANGUAGE ATTITUDES AND POLICIES, INCLUDING OFFICIAL STATUS AND USE}

In the states of Meghalaya and Assam the Koch language has no declared official status. The educational system provided by the Government of Meghalaya has no provision for the language. Koch Krorang Mathop (Koch Literary Society), Meghalaya Koch Association and other village level organizations (especially in West Garo Hills and South-West Garo Hills districts) with their sole initiative practise the use of the Koch language in creative literatures. As reported earlier Koch is nowhere taught in the three states-Assam, Meghalaya and West Bengal. A very limited use of the Koch language is evident in mass media.

i. Non-governmental effort is evident for the promotion of the Koch language. The various educational activities like publishing books, primers, language teaching materials are attested by Koch Krorang Mathop and Meghalaya Koch Association.

ii. Meghalaya Koch Student's Union (MKSU), Meghalaya Koch Women's Organization, All Assam Koch Student's Union, All Assam Koch Association, All Assam Koch Mahila Parisad also work for the development of the language and culture. They have taken initiative to promote the language and culture as a part of the revivalist program.

iii. As a part of the developmental program of the language, efforts of the individual scholars like Koch Ratna Late Sibendra Narayan Koch, Nirmal Koch, Dhiraj Banai, Alexander Kondakov, Umendra Koch, Ambika Koch, Jibesh Dusa Koch, Nityananda Chiku, Utpal Koch, Kamal Narayan Koch, Kamaleswar Koch, Abonath Koch, Upen Hari Koch and Late Khalin Koch are worth mentioning. 


\subsection{TYPE AND QUALITY OF DOCUMENTATION}

The maximum number of publication in the Koch language is found in case of periodicals/magazines. Teaching materials of the Koch language like dictionary and grammar are available, though a recent development. Book of conversation in Koch is also available. There are four text books in Koch, of which three are primers and one book of mathematics. Translation works from religious texts, epic, popular tales, songs from the Bengali language to Koch are also found. Apart from these books of songs, poems and drama are also available in the language. Though the publication in the Koch language started in 1973 with the publication of a poem by Nirmal Koch in a magazine called 'Rasan', the publication actually started gaining ground in the twenty first century and received impetus in the second decade of the century. Maximum number of publication available in the Koch language is found in case of magazines/periodicals.

\subsection{RESPONSE TO NEW DOMAINS AND MEDIA}

An initiative is being taken by Koch Krorang Mathop for the upliftment of the language and culture of the Koch language. Planning to teach the Koch language formally meant for all age groups is a recent development. Apart from this no other response of the language to new domains has been observed.

Response to media (both print media and audio-visual media) is attested by the language. The use of Koch in media is discussed below.

(i) Periodicals/Magazines and Souvenirs are available in Koch. These are mainly published by Koch Krorang Mathop (Koch Literary Society) and Meghalaya Koch Association during meetings and conferences. These are not always exclusively in Koch, but these are often bi-lingual/trilingual where Bengali and Assamese are the languages in most cases along with English in some cases.

(ii) News -sheets/papers are not available in Koch. As regards documentation of the Koch language in audio-visual media, some audio-visual recording of songs have been produced in Koch. There are no films in the language produced till date. Documentation of Koch folk songs and folk dances are available which are found to telecast during Koch festivals.

\subsection{AVAILABILITY OF MATERIALS FOR LANGUAGE EDUCATION AND LITERACY}

For education and literacy in Koch there are only three primers. Book on mathematics is also available in the Koch language.

Language teaching materials like bilingual dictionaries, short grammatical sketches, book on conversation are available in Koch. These are mainly produced with individual effort and by SIL International. 


\subsection{PROPORTION OF SPEAKERS WITHIN THE TOTAL POPULATION}

According to 2011 census the total Koch scheduled tribe population pertaining to the state of Meghalaya (where the majority of the speakers are located) is 22,716. But the total number of speakers returning Koch as the mother tongue is 36,434. Therefore, the proportion of Koch speakers and the Koch scheduled tribe population is 1: 1.6. The ST population of Koch is much lower than the speakers' strength of the language. Such a situation is indicative of language maintenance.

\section{CONCLUSION}

Koch as a language of a minor tribal community inhabiting in both the hilly region of Garo Hills district of Meghalaya came under the influence of Bengali, Assamese, Garo, Hajong, etc. at different points of time in the history. Koches could not maintain their identity in the northern part of West Bengal, they could maintain their separate tribal identity in the Garo Hills of Meghalaya only and in some villages of Assam bordering Meghalaya. In West Bengal they have merged with the Indo-Aryan speeches of the area, which they call 'Rajbangsi'. With the passage of time due to the change in the socio-political scenario, Koch was influenced by different languages at different domains of social life. But the dominant influence of the Assamese and the Bengali language did not lead the Koch language to lose its hold in the social domains of Koch life in Meghalaya. Language shift is mainly evident among the Koches of Assam. The interplay of time and space cultivated the sense of inequality among the Koch people and this has given rise to a crisis which is socio-linguistic in nature. It has been reported that lack of government support is making the situation more and more difficult regarding the maintenance of the language. It is hoped that the study of ethno-linguistic vitality of Koch will provide positive impact on framing language policy on the part of the government.

\section{ACKNOWLEDGEMENTS}

I am grateful to Indian Council of Social Science Research (ICSSR), New Delhi for granting me a project on 'Socio-linguistic Profile of Koch', the paper being an outcome of the project. I also convey my gratitude to my teacher, Prof. Shyam Sundar Bhattacharya for his guidance and insightful comments since the inception of the project.

\section{REFERENCES}

Damant, G. H. 1880. 'Notes on the Locality and Population of the Tribes dwelling between Brahmaputra and Ningthi Rivers', Journal of the Royal 
Asiatic Society. XII. In: www.linguistics.berkley.edu/dwbruhn/STEDT/ Damant 1880 notes tribees.pdf. (Accessed on 03.06.2016).

Dattamajumdar, $\bar{S} .200 \overline{3}$. 'Language Attitude of Indian Expatriates in UAE: A Socio-Economic Perspective', Indian Journal of Dravidian Linguistics. Vol. XXXII, No. 1: 49-62.

Dattamajumdar, S. 2016. An Enquiry into the Status of Lepcha. Kolkata: The Asiatic Society.

Dattamajumdar, S. 2018. Exploring Ethno-linguistic Vitality: A Study of the Nature and Extent of Endangerment in Tiwa (Lalung) Language. Kolkata: The Asiatic Society.

Fasold, R. 1984. The Sociolinguistics of Society. Oxford: Basil Blackwell.

Giles, H., R. Y. Bourhis and D. M. Taylor 1977. 'Towards a Theory of Language in Ethnic Group Relations'. In: H. Giles (ed.) Language, Ethnicity and Intergroup Relations. pp. 307-343. London, New York \& San Fransisco: Academic Press.

Grierson, G. A. 1903. Linguistic Survey of India. Vol. III, Pt. II.:49-55. Delhi Varanasi Patna: Motilal Banarasidass.

http//www.unesco.org/new/en/culture/themes/endangered-languages-vitality/ (accessed on 05.09.2010 at 11:40 hrs).

Kim, S., S. Ahmad, A. Kim and M. Sangma 2011. The Koch of Bangladesh: A Sociolinguistic Survey. SIL International Electronic Survey Report 2011023, March 2011.

Kloss, H. 1966. 'Types of Multilingual Communities: A Discussion of Ten Variables', Sociological Inquiry. Vol. 36(2): 135-145.

Kloss, H. 1967. 'Abstand Languages and Ausbau Languages', Anthropological Linguistics. Vol. 9(7): 29-41.

Koch, A. 2013. Koch Bak-Botni, a Koch Conversation. Khalpara, Meghalaya: Vivekananda Koch.

Koch, A. 2014. Koch Koro'mukpak, a Koch Grammar. Dhubri, Assam: Jibesh Koch.

Koch, K. N. (comp.) 2016. A Concise Lexicon of Koch Mandai Language. Assam, Barpeta: Koch Mandai Language Development Academy.

Koch, S. N. 1984. The Koches of Garo Hills. In: L. S. Gassah (ed.) Garo Hills: Land and the People. pp. 175-182. New Delhi: Omsons Publications.

Koch, U. 2003. Kro-Rungtak. Koch into English and Assamese. Meghalaya, Tura: Koch Krorang Mathop.

Kondakov, A. (comp. \& ed.) 2018. Koch-English Dictionary. SIL International.

Kondakov, A. 2013. Koch Dialects of Meghalaya and Assam: A Sociolinguistic Survey. In: G. Hyslop, S. Morey and M. W. Post (eds.) North East Indian Linguistics. Vol. 5. pp. 3-59.

Kondakov, A. and N. Koch (eds.) 2009. De, Kocho Koro Bakna - Let's Speak Koch. SIL International.

Martin, E. 2009. 'An Evaluation Matrix for Ethnolinguistic Vitality'. In: S. Petrot, T. Priestly and C. Williams (eds.) Rights, Promotion and 
Integration Issues for Minority Languages in Europe. pp. 123-127. U.K., London: Palgrave Macmillan Ltd.

McConnell, G. D. 1987. A Macro-sociolinguistic Analysis of Language Vitality: Geolinguistic Profiles and Scenarios of Language Contact in India. Unpublished dissertation. Universite Laval.

Mondol, A. B. 2010. Koch Bhasa Gosthir Kathita Bhasa aru Loka Sahitya: Eti Adhyayan. Doctoral dissertation. (written in Assamese). Guwahati: Gauhati University.

Wurm, S. A. 1993. Information Document. The Red book of Languages in Danger of Disappearing. UNESCO. 
